\title{
How to monitor thiopental administration in the intensive care unit for refectory status epilepticus or intracranial hypertension?
}

\author{
Erika Dabricot ${ }^{1 \dagger}$, Inès Seqat ${ }^{2 \dagger}$, Frédéric Dailler ${ }^{1}$, Sylvain Rheims ${ }^{2,3}$, Sebastien Boulogne ${ }^{2,3}$ and \\ Baptiste Balança $a^{1,3^{*}}$ (])
}

\begin{abstract}
Dear editor,
Thiopental continuous administration can be used as a rescue therapy for refractory status epilepticus (SE) or intracranial hypertension (IH). It induces an electroencephalographic (EEG) slowing up to a burst suppression state. The subsequent reduction in the cerebral metabolic demand and blood flow also allows decreasing the intracranial pressure (ICP) [1]. The continuous administration is usually guided both by thiopental serum concentration, to avoid accumulation, and efficacy on seizures or ICP. Thiopental side effects (hemodynamic dysfunction or immunosuppression) can occur at concentrations of $30-70 \mathrm{mg} / \mathrm{ml}[2,3]$. Conversely, the relation between serum concentrations and efficacy is less robust. In healthy subjects during anesthesia and in brain-injured patients, there is a great variability in the concentration needed to reach the same EEG changes $[4,5]$, with an overlap between the therapeutic and toxic ranges. The digitalization of the EEG signal provides quantitative indexes at the bedside and may allow tailoring sedative administration in the intensive care unit (ICU). For instance, the suppression ratio (SR) provides a metric of the depth of sedation during general anesthesia [5]. Since the target of thiopental sedation is to reach a discontinuous EEG activity (i.e., $\mathrm{SR} \geq 10 \%$ ); the aim of the herein
\end{abstract}

*Correspondence: baptiste.balanca@chu-lyon.fr

†Erika Dabricot and Inès Seqat have contributed equally to this work

1 Department of Neurological Anesthesiology and Intensive Care,

Hospices Civils de Lyon, Hôpital Pierre Wertheimer, Groupement Hospitalier Est, 59 Boulevard Pinel, 69500 Bron, Lyon, France

Full list of author information is available at the end of the article study was to evaluate the relationship between the thiopental concentration and the SR in patients with a refractory SE or IH.

We conducted a retrospective study (2013-2020) in adult patients sedated with thiopental and monitored with a continuous EEG, in the neurological ICU of the Hospices Civils de Lyon (France). We analyzed EEG signals of $2 \mathrm{~h}$ windows around the serum measurements $(1 \mathrm{~h}$ before and after). Suppression periods were defined by an EEG amplitude $<10 \mu \mathrm{V}$ for $\geq 400 \mathrm{~ms}$ [6] and was calculated on $2 \mathrm{~s}$ epochs on the central derivation with the best signal (Fz-Cz or adjacent; BRAIN-QUICK, Micromed). We took the mean SR of the $2 \mathrm{~h}$. The relation between concentration and duration of thiopental administration and the SR was analyzed with a linear mixed effect model with the $\mathrm{R}$ software (lme4 library). The diagnostic accuracy of thiopental concentration to predict a discontinuous EEG was analyzed with a receiver operating characteristic curve (ROC, pROC library). Data are presented as their median and interquartile range.

We included 30 patients, $47 \%(n=14 / 30)$ had a refractory SE. They were 39.5 years old [27.5-55.5], $30 \%(n=9)$ were female, and $37 \%$ had a potent thiopental adverse effect (sepsis: $n=5$; hemodynamic instability: $n=6$ ). The median concentration of thiopental ( $n=95$ samples) was $16.5 \mathrm{mg} / \mathrm{ml}[8.5-23.1]$, with a median administration rate of $2.1 \mathrm{mg} / \mathrm{kg} / \mathrm{h}[1.3-2.9]$. At the blood sampling time, $45.3 \%(n=43 / 95)$ of the EEG were discontinuous with heterogeneous SR decay time (Fig. 1). 74\% of the EEG from patients with a SE did not have epileptic discharges and $68 \%$ of patients with an original author(s) and the source, provide a link to the Creative Commons licence, and indicate if changes were made. The images or other third party material in this article are included in the article's Creative Commons licence, unless indicated otherwise in a credit line to the material. If material is not included in the article's Creative Commons licence and your intended use is not permitted by statutory regulation or exceeds the permitted use, you will need to obtain permission directly from the copyright holder. To view a copy of this licence, visit http://creativecommons.org/licenses/by/4.0/. The Creative Commons Public Domain Dedication waiver (http://creativeco mmons.org/publicdomain/zero/1.0/) applies to the data made available in this article, unless otherwise stated in a credit line to the data. 


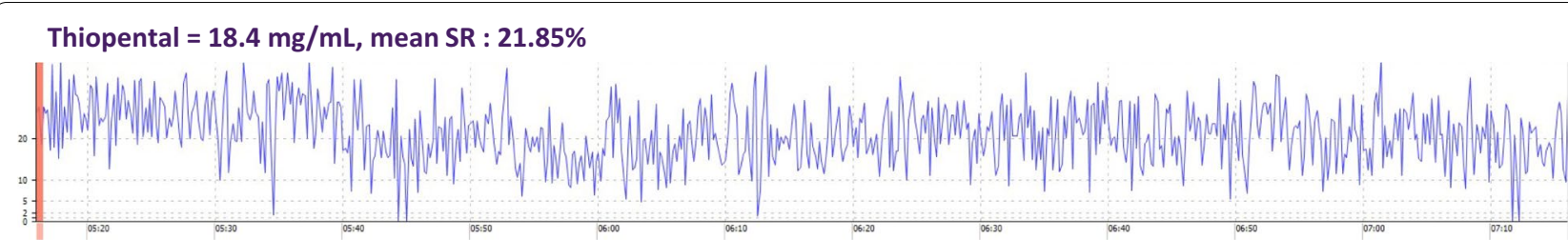

Thiopental $=6.0 \mathrm{mg} / \mathrm{mL}$, mean SR : $27.23 \%$

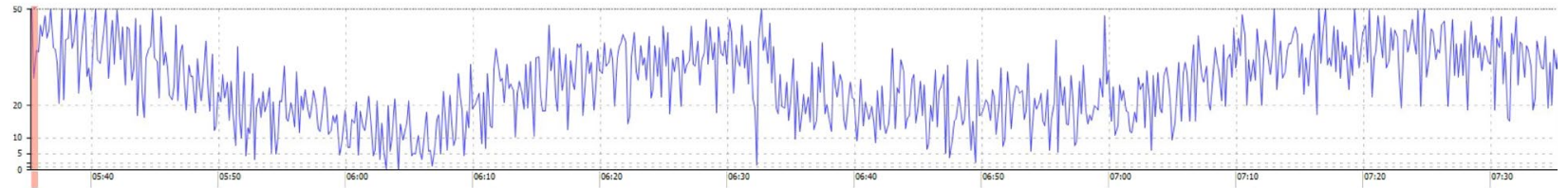

Thiopental $=7.2 \mathrm{mg} / \mathrm{mL}$, mean SR : $10.34 \%$
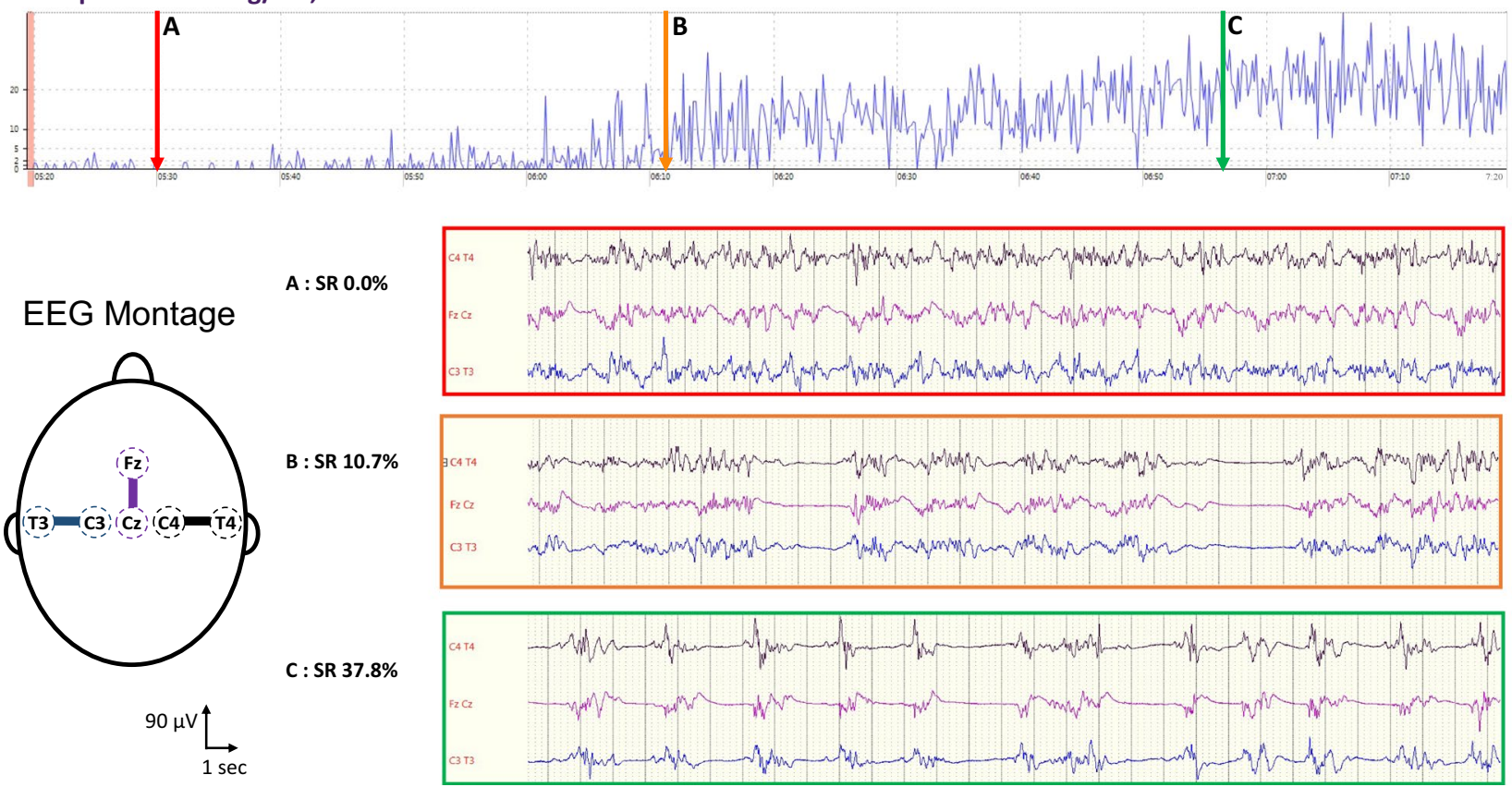

Fig. 1 Examples of suppression ratio (SR) changes during the $2 \mathrm{~h}$ surrounding the blood sample time. Three different examples of SR changes are plotted in blue. The first two curves show similar SR in the same patient with a constant midazolam infusion, whereas thiopental concentrations vary by a ratio of 3. The last curve of another patient without midazolam, shows a different SR decay while the thiopental concentration is comparable to the one of the second curve. The lower panel presents three raw EEG samples of the lower SR curve (arrows A, B and C) using three bipolar derivations (right: C4-T4, midline: $\mathrm{Fz}-\mathrm{Cz}$, and left: C3-T3, see EEG montage of the left) with a $0.53 \mathrm{~Hz}$ high-pass filter and an $80 \mathrm{~Hz}$ low-pass filter

IH had an ICP $<25 \mathrm{mmHg}$. The ICP value was not significantly associated with the thiopental concentration. There was a significant association between thiopental concentration and SR, which was not dependent on the indication (SE or IH). However, for a given thiopental concentration, the level of SR was highly variable and thiopental concentration could not predict a discontinuous EEG (AUC of the ROC $=0.59$ 95\%CI [0.47; 0.71], Fig. 2). Other sedative agents were also administered in
20 patients but did not significantly influence SR; their withdraw led to a SR decrease in 4 cases.

The main limitation of the herein study is its retrospective design. Given the heterogeneity of the EEG changes for a given thiopental administration, we would argue to have a continuous SR monitoring when using barbiturate to reach a discontinuous activity. The concomitant monitoring of electrophysiological data and serum concentration might help tailor the individual administration and monitor the effect of thiopental 

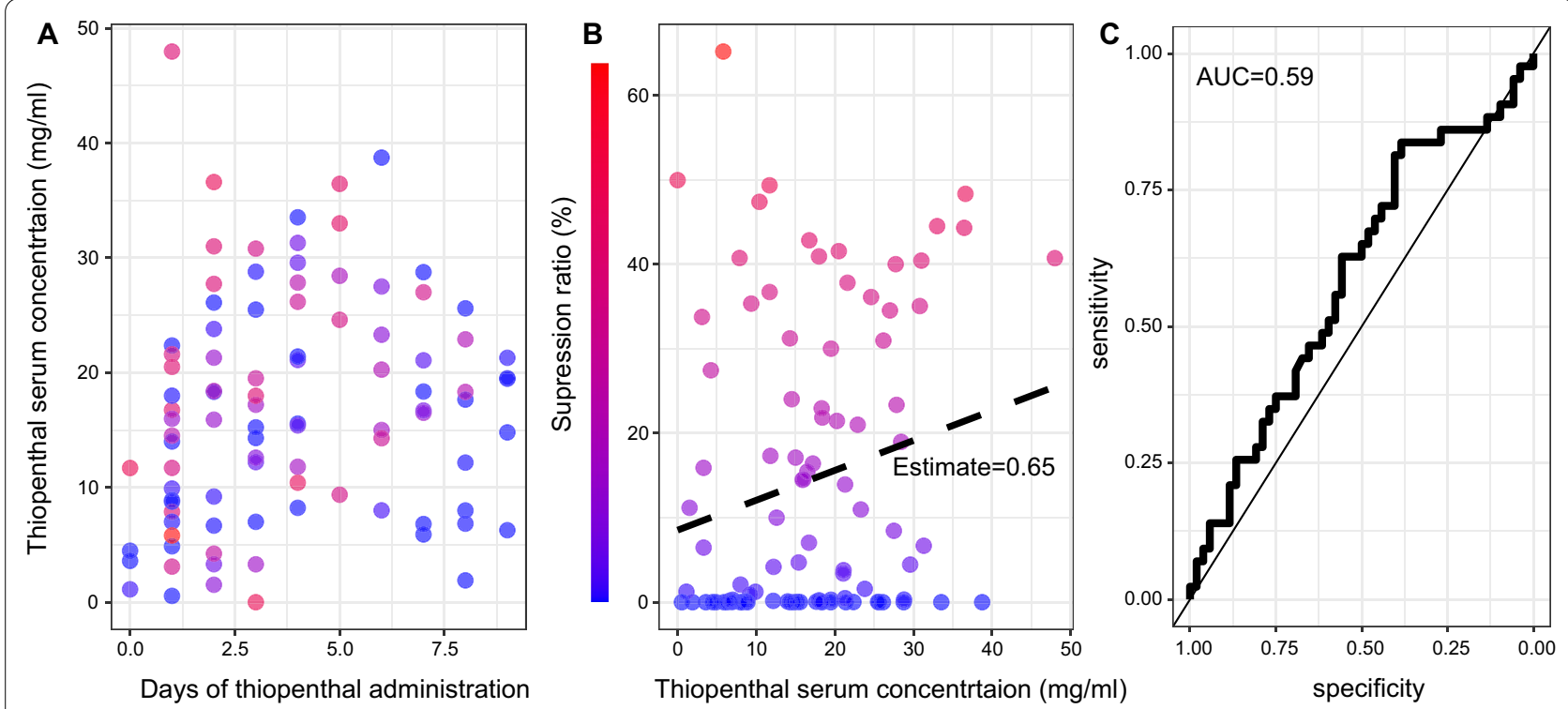

Fig. 2 Suppression ratio and thiopental serum concentration relationship. A Thiopental serum concentration changes during the first ten administration days. The dot color represents the suppression ratio at the sampling time (the color scale is on the $\mathbf{B}$ panel). B Mean suppression ratio of the $2 \mathrm{~h}$ EEG time window around the blood sampling time of the thiopental serum concentration ( $x$-axis). The dashed line represents the slope of the linear regression model (Estimate $=0.6595 \% \mathrm{Cl}[0.09 ; 1.21], p=0.02)$. C Receiver operating characteristic curve of thiopental serum concentration to predict a $\mathrm{SR} \geq 10 \%$ (AUC $=0.5995 \% \mathrm{Cl}[0.47 ; 0.71])$

on brain activity. Such strategy will need to be evaluated in a prospective trial.

\section{Acknowledgements}

Not applicable.

\section{Authors' contributions}

$B B, E D, I S$ and SB conceived and design the study. ED collected the data from digital medical records. IS and SB reviewed electrophysiological data. BB analyzed the data. BB, ED, IS and SB interpreted the data. ED and BB draft the article. All authors critically revised the article. All authors approved the final version to be published.

\section{Funding}

Not applicable.

\section{Availability of data and materials}

The datasets used during the current study are available from the corresponding author on reasonable request.

\section{Declarations}

\section{Ethics approval and consent to participate}

The study was approved by the Ethics Committee of the French Intensive Care Society (No. IRB 00010254-2021-032).

\section{Consent for publication}

Not applicable.

\section{Competing interests}

The authors declare that they have no competing interests.

\section{Author details}

${ }^{1}$ Department of Neurological Anesthesiology and Intensive Care, Hospices Civils de Lyon, Hôpital Pierre Wertheimer, Groupement Hospitalier Est,

59 Boulevard Pinel, 69500 Bron, Lyon, France. ²Department of Functional
Neurology and Epileptology, Hospices Civils de Lyon and Lyon 1 University, Lyon, France. ${ }^{3}$ Lyon's Neuroscience Research Center, INSERM U1028/CNRS UMR 5292, Lyon 1 University, Lyon, France.

Received: 27 October 2021 Accepted: 1 December 2021

Published online: 17 December 2021

\section{References}

1. Russo H, Bressolle F. Pharmacodynamics and pharmacokinetics of thiopental. Clin Pharmacokinet. 1998;35:95-134.

2. Huynh F, Mabasa VH, Ensom MHH. A critical review: Does thiopental continuous infusion warrant therapeutic drug monitoring in the critical care population? Ther Drug Monit. 2009;31:153-69.

3. Parviainen I, Uusaro A, Kälviäinen R, Kaukanen E, Mervaala E, Ruokonen E. High-dose thiopental in the treatment of refractory status epilepticus in intensive care unit. Neurology. 2002;59:1249-51.

4. Winer JW, Rosenwasser RH, Jimenez F. Electroencephalographic activity and serum and cerebrospinal fluid pentobarbital levels in determining the therapeutic end point during barbiturate coma. Neurosurgery. 1991;29:739.

5. Bührer M, Maitre PO, Hung OR, Ebling WF, Shafer SL, Stanski DR. Thiopental pharmacodynamics I. Defining the pseudo-steady-state serum concentration-EEG effect relationship. Anesthesiology. 1992;77:226-36.

6. Särkelä M, Mustola S, Seppänen T, Koskinen M, Lepola P, Suominen K, et al. Automatic analysis and monitoring of burst suppression in anesthesia. J Clin Monitor Comp. 2002;17:125-34.

\section{Publisher's Note}

Springer Nature remains neutral with regard to jurisdictional claims in published maps and institutional affiliations. 